\title{
Oxalate-assisted synthesis of nano cobalt oxide
}

F. Manteghi ${ }^{*}$, M. Peyvandipour,

Department of Chemistry, Iran University of Science and Technology, Tehran, Iran

\begin{abstract}
Organic ligands are widely applied in preparation of metallic complexes, and in high temperatures, can be burned and eliminated from the coordination sphere, remaining only oxide group. In a reaction between cobalt nitrate, ammonium oxalate and F-127 as a surfactant to control the particles size, a cobalt-oxalate complex was formed. After performing Thermal Gravimetric Analysis (TGA) to find the optimum decomposition temperature, the precipitate was calcined and the resulted nano cobalt oxide was characterized by Fourier Transform Infrared spectroscopy (FTIR), Scanning Electron Microscopy (SEM), X-ray Diffraction (XRD). The crystalline pure and nanosized particles had the average size $<40 \mathrm{~nm}$.

Oxalic acid, Nano cobalt oxide, Surfactant
\end{abstract}

\section{Introduction}

Cobalt oxide $\left(\mathrm{Co}_{3} \mathrm{O}_{4}\right)$ is an important antiferromagnetic p-type semiconductor, which has a wide range of applications in various fields such as electrochromic devices, ceramic pigments, heterogeneous catalysts, solid-state sensors, magnetism, solar energy absorbers, and energy storage. It has already reported that size and morphology of $\mathrm{Co}_{3} \mathrm{O}_{4}$ extremely affect its properties and therefore many researchers aim to synthesize new shapes in nano scale [1]. Different nanoscale morphologies such as hollow nanospheres [2], cubic single crystals [3], fibers [4], particles [5], rods [6], tubes [7] and films [8] in nanoscale have been reported so far.

The spinel cobalt oxide $\mathrm{Co}_{3} \mathrm{O}_{4}$ is a magnetic semiconductor and widely used catalyst for a variety of reactions. $\mathrm{Co}_{3} \mathrm{O}_{4}$ crystallizes in the cubic normal spinel structure with magnetic $\mathrm{Co}^{2+}$ ions in tetrahedral sites and non-magnetic $\mathrm{Co}^{3+}$ ions in octahedral sites.Several other methods have also been used for the synthesis of spinel $\mathrm{Co}_{3} \mathrm{O}_{4}$ nanoparticles such as sol-gel method, polyol process, solvothermal synthesis, polymer assisted synthesis, thermal decompositions and hydrothermal synthesis for $\mathrm{Co}_{3} \mathrm{O}_{4}$ nanorods [9-14].

In this work, we report the synthesis of nano-rod $\mathrm{Co}_{3} \mathrm{O}_{4}$ through co-precipitation method via thermal decomposition of cobalt oxalate synthesized from $\mathrm{Co}\left(\mathrm{NO}_{3}\right)_{2} \cdot 6 \mathrm{H}_{2} \mathrm{O},\left(\mathrm{NH}_{4}\right)_{2} \mathrm{C}_{2} \mathrm{O}_{4}$ and F-

\footnotetext{
* Corresponding author:

Email: $f$ manteghi@iust.ac.ir (Faranak Manteghi)

Tel: +98 (21) 77240516-7

Fax: +98 (21) 77491204
} 
127 as surfactant, while the molar ratio of ammonium oxalate to metal precursor was $1: 1$. The pink precipitate was finally calcined at $400^{\circ} \mathrm{C}$. The structural properties of the $\mathrm{Co}_{3} \mathrm{O}_{4}$ were investigated by Fourier Transform InfraRed spectroscopy (FTIR), Scanning Electron Microscopy (SEM), X-Ray Diffraction (XRD) and Thermal Gravimetric Analysis (TGA). Experimental results revealed that $\mathrm{Co}_{3} \mathrm{O}_{4}$ nanoparticles could successfully synthesized with good crystallinity and with the average size of about $38 \mathrm{~nm}$.

\section{Experimental}

All materials purchased from MERCK was used without any further purification. To an aqueous solution of $0.5 \mathrm{~g} \mathrm{Co}\left(\mathrm{NO}_{3}\right)_{2} \cdot 6 \mathrm{H}_{2} \mathrm{O}$ was rapidly added an $\left(\mathrm{NH}_{4}\right)_{2} \mathrm{C}_{2} \mathrm{O}_{4}$ and $\mathrm{F}-127$ solution. The mole ratio of two salts was $1: 1$. For investigating the effect of temperature and surfactant on morphology and size of $\mathrm{Co}_{3} \mathrm{O}_{4}$ particles, we exert different temperatures as $25^{\circ} \mathrm{C}, 40^{\circ} \mathrm{C}, 80^{\circ} \mathrm{C}$ and also, $25^{\circ} \mathrm{C}$ in presence of $\mathrm{F}-127$. After stirring for $4 \mathrm{~h}$, the precipitates were collected by filtration and washed with distilled water; finally $\mathrm{Co}_{3} \mathrm{O}_{4}$ was obtained by calcining the precipitates in air at $400^{\circ} \mathrm{C}$.
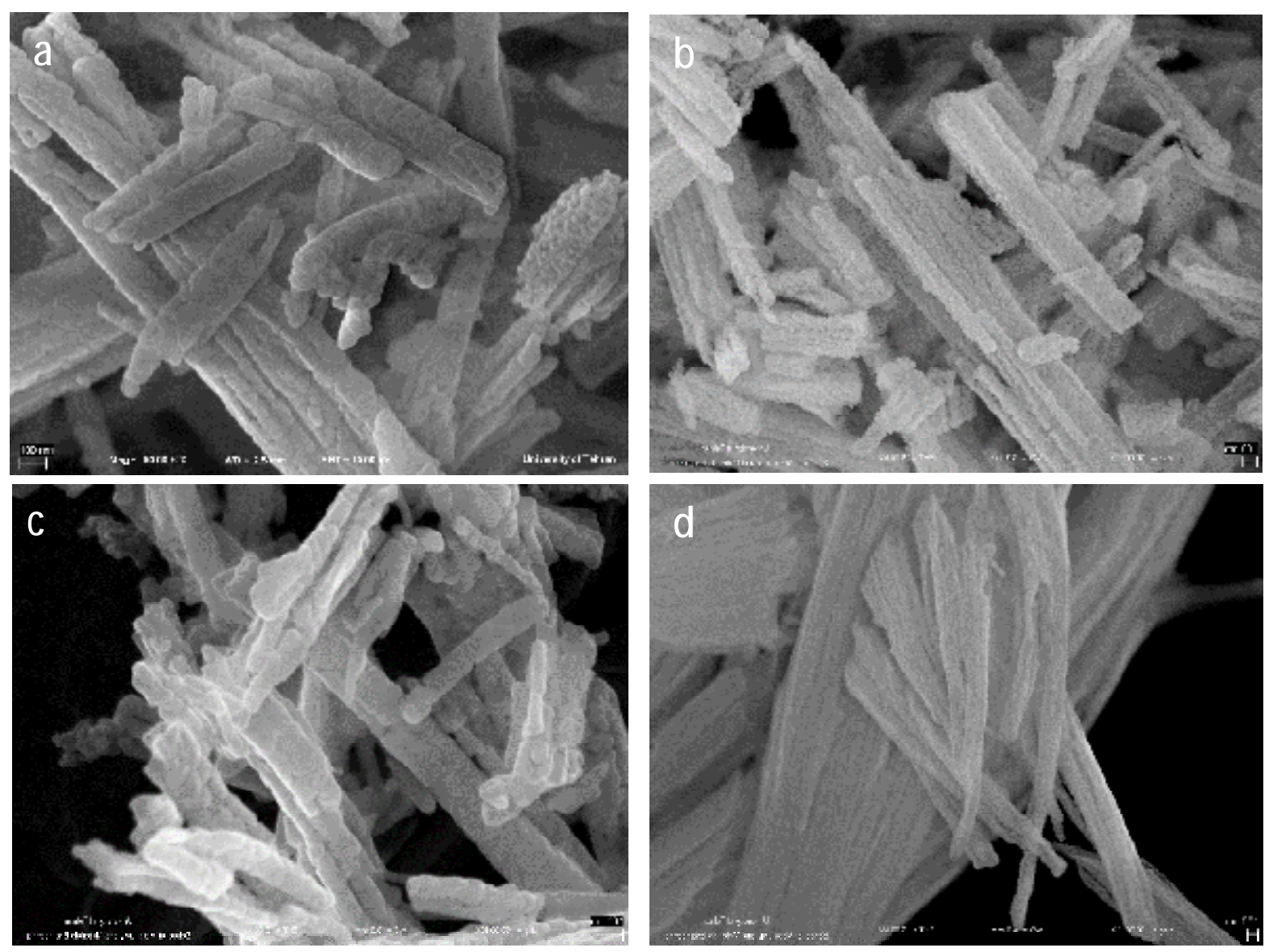

Fig. 1. SEM images of the prepared $\mathrm{Co}_{3} \mathrm{O}_{4}$ nanorods at a) $25^{\circ} \mathrm{C}$, b) $40^{\circ} \mathrm{C}$, c) $80^{\circ} \mathrm{C}$ and d) $25^{\circ} \mathrm{C}$ in the presence of $\mathrm{F}-127$. 
The addition of ammonium oxalate to the solution of cobalt nitrate provokes the precipitation of a pink cobalt oxalate complex characterized by FTIR spectrum in which a broad band at 3.373 $\mathrm{cm}^{-1}$ is assigned to both the $v_{\mathrm{s}}(\mathrm{O}-\mathrm{H})_{\mathrm{s}}$ and $v_{\text {as }}(\mathrm{O}-\mathrm{H})$ vibrations in crystal water molecules. An intense band at $1.623 \mathrm{~cm}^{-1}$ is assigned to asymmetric $v_{\text {as }}(\mathrm{C}-\mathrm{O})$, two closely spaced bands at $1.359-1.317 \mathrm{~cm}^{-1}$ to $v_{\mathrm{s}}(\mathrm{C}-\mathrm{O})$ and the band at $825 \mathrm{~cm}^{-1}$ to the $\delta(\mathrm{OCO})$, characteristic of bridging oxalate groups. The band at $493 \mathrm{~cm}^{-1}$ may be attributed to Co-O stretching.

$\mathrm{Co}_{3} \mathrm{O}_{4}$ was obtained by calcining the precipitates in air at $400^{\circ} \mathrm{C}$. IR spectrum of cobalt oxide has the peaks at 572 and $667 \mathrm{~cm}^{-1}$ corresponding to metal-oxygen (Co-O) vibrational modes of the spinel compound.

The TG/DTA measurements of cobalt oxalate and precursors were carried out to find out the suitable temperature for calcination of the precursors, as shown in Fig. 2. In the TG/DTA profiles of cobalt oxalate shown in Fig. 4, a mass loss rate of $18.47 \%$ can be observed from 148 to $200^{\circ} \mathrm{C}$ on the TG curve, which corresponds to abroad endothermic peak at around $190^{\circ} \mathrm{C}$ on the DTA curve. This is due to the dehydration of chemically bonded water in the $\mathrm{CoC}_{2} \mathrm{O}_{4} \cdot 2 \mathrm{H}_{2} \mathrm{O}$ complex. The second mass loss and the corresponding sharp exothermic peak occur at around $293^{\circ} \mathrm{C}$, indicating the decomposition and oxidation reaction of $\mathrm{CoC}_{2} \mathrm{O}_{4}$.

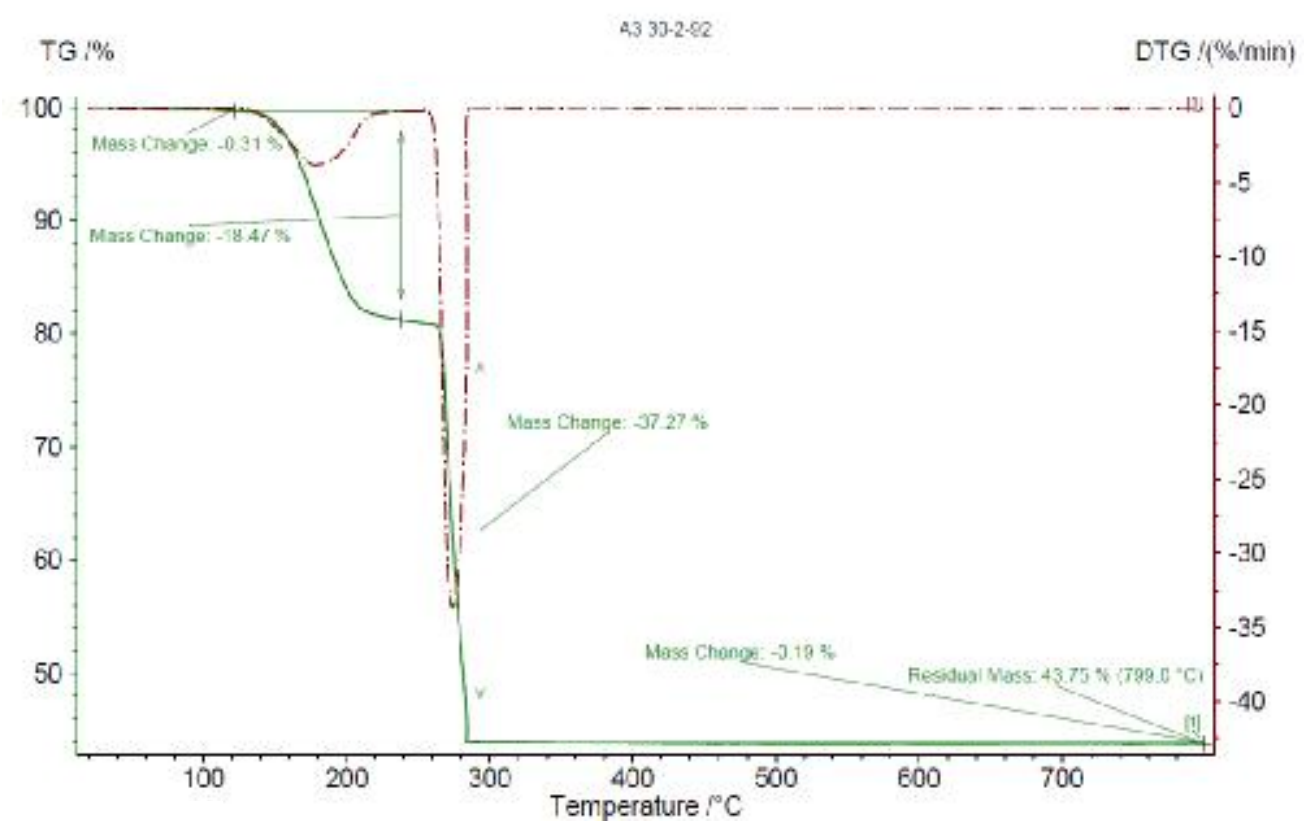

Fig. 2. TG/DTA profiles of cobalt oxalate.

Finally, the XRD pattern of $\mathrm{Co}_{3} \mathrm{O}_{4}$ synthesized at $25^{\circ} \mathrm{C}$ without surfactant is shown in Fig. 3. 


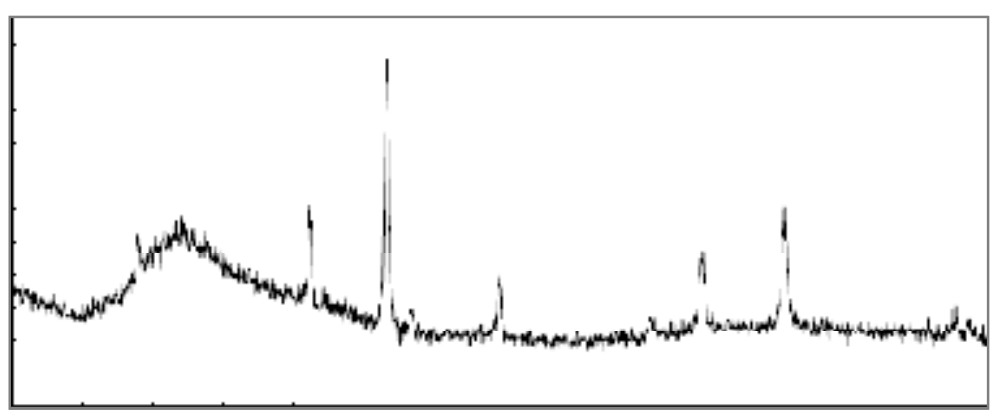

Fig. 3 XRD pattern of the $\mathrm{Co}_{3} \mathrm{O}_{4}$ nanoparticles prepared at $400{ }^{\circ} \mathrm{C}$

\section{Conclusion:}

The $\mathrm{Co}_{3} \mathrm{O}_{4}$ nanoparticles were prepared by thermal decomposition of cobalt oxalate. FT-IR analysis confirms the formation of the $\mathrm{Co}_{3} \mathrm{O}_{4}$ nanoparticles. The calcined cobalt oxide nanoparticles at $400{ }^{\circ} \mathrm{C}$ were characterized by using XRD which confirms the formation of $\mathrm{Co}_{3} \mathrm{O}_{4}$. The SEM of $\mathrm{Co}_{3} \mathrm{O}_{4}$ particles shows the nanorod particles. We showed different morphologies of $\mathrm{Co}_{3} \mathrm{O}_{4}$ that synthesized at different temperatures and conditions.

\section{Acknowledgements:}

The financial support of Iran University of Science and Technology is greatly acknowledged.

\section{References:}

[1] L. Ren, P. Wang, Y. Han, C. Hu, B. Wei, Chem. Phys. Lett. 476 (2009) 78.

[2] S.A. Makhlouf, J. Magn. Magn. Mater. 246 (2002) 184.

[3] P.A. George, S. Elias, D.D. Dionysios, J. Phys. Chem. B 109 (2005) 13052.

[4] B.B. Lakshmi, C.J. Patrissi, C.R. Martin, Chem. Mater. 9 (1997) 2544.

[5] R, Xu, H.C. Zeng J. Phys. Chem. B 107 (2003) 12643.

[6] Y. Liu, G. Wang, C. Xu, W. Wang, Chem. Commun. 2 (2002) 1486.

[7] X.S. Shi, S. Han, R.J. Sanedrin, C. Galvez, F. Zhou, M. Selke, Nano. Lett. 2 (2002) 289.

[8] A. Gulino, P. Dapporto, P. Rossi, I. Fragala, Chem. Mater. 15 (2003) 3748.

[9] P. Dutta, MS. Seehra, S. Thota, J. Kumar, J Phys Condens. Matter 20 (2008) 015218.

[10] C. An-Min, H. Jin- Song, L. Han-Pu, S. Wei-Guo, W. Li-Jun, H. Xiu-Li, et al., .J. Phys. Chem B 110 (2006) 15858.

[11] J. Park, X. Shen, G. Wang, Sens. Actuators B Chem. 136 (2009) 494. 
[12] Y. Chen, Y. Zhang, S. Fu, Mater. Lett. 61(3) (2007) 701.

[13] HH. Monfared, A. Morsali, J. Mol. Struct. 938 (2009) 4.

[14] G. Wang, X .Shen, J. Horvat, B. Wang, H. Liu, D. Wexler, J. Phys. Chem. C 113 (2009) 4357.

[15] C. Wei, C.-b. Wang, S.-H. Chien, Thermochim. Acta 473 (2008) 68. 